\title{
Substance Use as a Strong Predictor of Poor Academic Achievement among University Students
}

\author{
Tesfa Mekonen, ${ }^{1}$ Wubalem Fekadu, ${ }^{1}$ \\ Tefera Chane Mekonnen, ${ }^{2}$ and Shimelash Bitew Workie ${ }^{3}$ \\ ${ }^{1}$ Psychiatry Department, College of Health Sciences and Medicine, Bahir Dar University, Bahir Dar, Ethiopia \\ ${ }^{2}$ College of Health Sciences and Medicine, Wollo University, Dessie, Ethiopia \\ ${ }^{3}$ School of Public Health, College of Health Sciences and Medicine, Wolaita Sodo University, Wolaita Sodo, Ethiopia \\ Correspondence should be addressed to Tesfa Mekonen; smarthope1@gmail.com
}

Received 1 January 2017; Revised 7 May 2017; Accepted 16 May 2017; Published 7 June 2017

Academic Editor: Nicola Magnavita

Copyright (C) 2017 Tesfa Mekonen et al. This is an open access article distributed under the Creative Commons Attribution License, which permits unrestricted use, distribution, and reproduction in any medium, provided the original work is properly cited.

\begin{abstract}
Background. Substance use is a growing concern globally and its association with students' academic performance is not well studied. Objective. This study was aimed to assess the prevalence of substance use (alcohol, tobacco, and khat) and its association with academic performance among university students. Methods. Cross-sectional study was conducted among Wolaita Sodo University students. A total of 747 students were selected by using cluster sampling technique. Data were collected by pretested self-administered questionnaire and examined using descriptive statistics and linear regression with 95\% confidence intervals. Variables with $p$ value of less than 0.05 were considered as statistically significant. Result. Prevalence of substance use (alcohol, tobacco, and khat) was $28.6 \%$. Substance use (current smoking, chewing khat at least weekly, drinking alcohol on a daily basis, and having intimate friend who uses substance) was significantly and negatively associated with students' academic performance. Conclusion. Substance use among Wolaita Sodo University students was as common as other studies in Sub-Saharan countries and negatively associated with students' academic achievement. The common practice of substance use and its association with poor academic performance demand the universities to have a good control of substance and to implement youth friendly activities.
\end{abstract}

\section{Background}

According to world health organization, psycho active substance is any chemical substance which alters physical and/or mental function. Substance abuse is also defined by DSM-V as use of any drug, usually by self-administration, in a manner that deviates from approved social or medical patterns $[1,2]$.

For different reasons, substance use has been practiced by students regardless of the negative consequences [3]. Use of psycho active substances such as khat (Catha edulis, which is evergreen leaf common in east Africa), tobacco products (cigarette, shisha), and alcoholic beverages have become major public health challenge [4].

Student substance use is associated with different factors like sex, age, peer pressure, family substance abuse, personal pleasure, and poor academic achievement $[3,5,6]$. According to the national youth risk behavior survey, USA, negative association was seen between alcohol and other drug use and academic achievement after controlling for sociodemographic variables [7]. Another study conducted in USA school adolescents indicated that students who were engaged in different substance use practices were poor academic achievers [8]. A study conducted at Jimma University also showed that substance use was associated with poor academic achievement [9].

Despite some researchers suggesting that substance use is associated with poor academic performance, many students used variety of substances for the sake of good academic achievement $[3,10]$. As a study conducted in Turkey indicates, substance use was practiced by significant proportion of university students; cigarette was smoked by $24.8 \%$ students regularly every day; alcohol was drunk occasionally by $37.8 \%$ of university students and by $8.1 \%$ of students regularly [11]. In Iran substance (alcohol, cigarette, and water pipe) was 
used by $22 \%$ male medical students and $8 \%$ female medical students at least once in their life [12]. Alcohol was consumed daily by $42 \%$ of Osun State University students in Nigeria and $34.1 \%$ of students consumed alcohol weekly. As a research done in South Africa showed the occurrence of alcohol use was $38.7 \%$, tobacco smoking $30 \%$, and cannabis was $8.4 \%$ [13].

Different substances like khat, alcohol, and tobacco products have been consumed by significant proportions of university students in Ethiopia. A cross-sectional study among undergraduate medical students of Addis Ababa University indicated that the lifetime prevalence of khat user was $14.1 \%$ [4]. The prevalence of khat chewing among Axum University students, North Ethiopia, was 27.9\% [14]. According to the study conducted among eastern Ethiopian school adolescents, study conducted in undergraduate medical students of Addis Ababa University and Axum University students, the lifetime prevalence of cigarette smoking was $12.4 \%, 8.7 \%$, and $9.3 \%$; from those $4.2 \%, 1.8 \%$, and $9.3 \%$ were daily smokers, respectively $[4,14,15]$. The research done in eastern Ethiopia showed the lifetime prevalence of cigarette smoking among school adolescents as $12.2 \%$ [16].

Since the proportion of student population in higher educational institutions is increasing, substance use and its association with academic performance is going to be an increased concern. As a good alert for universities and policymakers about the effect of substance use on academic performance; the result of this study will play a paramount role to conduct interventional measures with evidence based actions. Hence, the main purpose of this study was to assess the prevalence of substance use and its association with academic achievement among university students.

\section{Method}

Cross-sectional study was conducted at Wolaita Sodo University from February 10 to 20, 2015. Wolaita Sodo University is located in the mid highlands of south Ethiopia. Specifically, it is found in Wolaita Zone, with coordinate $\left(6^{\circ} 49^{\prime} \mathrm{N}\right.$ latitude and $37^{\circ} 45^{\prime} \mathrm{E}$ longitude) which lies approximately $330 \mathrm{KM}$ south of Addis Ababa.

The sample was calculated by using single population proportion formula. A $32.8 \%$ rate of substance use was taken from a study conducted at Axum University students with a margin of error 5\%, confidence level $95 \%$, and nonresponse rate of $10 \%$. By considering design effect of the two, the final sample size was 747 .

The study participants were recruited by cluster sampling method. Each department (section) from each college and school regardless of their academic year were listed and finally the section was taken as cluster which was selected randomly by lottery method.

The variables studied under this study were academic performance which was the dependent variable and the main independent variable was students' substance use. Other covariates were socioeconomic status of the students, peer pressure, origin of residence, any chronic illness, year of study, and parents' substance use.
For the sake of this research, substance use was defined as using either khat (Catha edulis), tobacco products or alcoholic beverages or any combination of those substance. When the study participants used substances (alcohol, chat, or tobacco) even once in their life, it was defined as lifetime use. Current use of substance is when the study participants were using those substances in the last 12 months from the data collection time $[17,18]$.

The data were collected by pretested self-administered questionnaire by well-trained data collectors. The questionnaire for substance use was adopted from WHO ASSIST [16, 17]. Academic achievement was assessed by students' CGPA (Cumulative Grade Point Average) scores at the end of the semester which were reported by the students. The students' CGPA is based on the Ethiopian higher education grading system which is scored out of 4 points. The questionnaire for sociodemographic and other variables was prepared from reviewed literatures.

The collected data were entered into Epi-Info version 3.5.2 and then transported to SPSS version 21 for further statistical analysis. Descriptive statistics were used for presenting the descriptive results. $T$-test with respective $p$ value was used to show the mean differences in CGPA. The variables were checked for uniformity, outliers, and multicollinearity, and the variance was normally distributed. Pearson correlation was used to see the correlation of substances with students' grade point. Those variables with $p$ value of less than 0.2 in univariate analysis were included and analyzed by multiple linear regression with 95\% confidence interval. Standardized and unstandardized regression coefficients were used to indicate the associations. Variables with $p$ values $<0.05$ were considered as statistically significant.

The ethical approval was obtained from Research Ethics Review Committee of College of Health Sciences and Medicine, Wolaita Sodo University. The purpose and importance of the study were explained for the participants and written consent was obtained from each participant. Confidentiality was maintained by anonymous questionnaire and by keeping the data in secure place.

\section{Results}

3.1. Sociodemographic Characteristics of the Study Participants. From the selected 747 participants 725 were involved in the study which makes the response rate 97.05\%. Among the total 725 participants, $482(66.5 \%)$ were male and the mean age was 21.18 years ( $\mathrm{SD} \pm 1.79$ years). From the total participants $343(47.3 \%)$ were protestant in their religion, $585(80.7 \%)$ were single in their marital status, and 191 (26.3\%) were Wolaita in their ethnicity. The reported monthly pocket money of the participants was ranged from 0 to 3600 Ethiopian birr with median value of 200 Ethiopian birr (Table 1).

3.2. Characteristics of Students' CGPA. The Cumulative Grade Point Average of the students was ranged from 1.70 to 3.98. The mean score of students' CGPA was $2.93( \pm 0.52)$. From the total students who participated in the study, 240 (33.1\%) of them had used at least one substance in their 
TABLE 1: Sociodemographic characteristics of Wolaita Sodo University students, 2015.

\begin{tabular}{|c|c|c|}
\hline Variable & Frequency $(n)$ & Percent (\%) \\
\hline \multicolumn{3}{|l|}{ Sex } \\
\hline Male & 482 & 66.5 \\
\hline Female & 243 & 33.5 \\
\hline \multicolumn{3}{|l|}{ Religion } \\
\hline Protestant & 343 & 47.3 \\
\hline Orthodox & 291 & 40.1 \\
\hline Muslim & 78 & 10.8 \\
\hline Catholic & 13 & 1.8 \\
\hline \multicolumn{3}{|l|}{ Marital status } \\
\hline Single & 585 & 80.7 \\
\hline In open relationship & 99 & 13.7 \\
\hline Married & 30 & 4.1 \\
\hline Divorced and widowed & 11 & 1.5 \\
\hline \multicolumn{3}{|l|}{ Monthly pocket money } \\
\hline$\leq 200 \mathrm{ETB}$ & 207 & 28.6 \\
\hline$>200 \mathrm{ETB}$ & 518 & 71.4 \\
\hline \multicolumn{3}{|l|}{ Ethnicity } \\
\hline Wolaita & 191 & 26.3 \\
\hline Oromo & 154 & 21.2 \\
\hline Amhara & 107 & 14.8 \\
\hline Gamo & 96 & 13.2 \\
\hline Sidama & 63 & 8.7 \\
\hline Gurage & 57 & 7.9 \\
\hline Hadya & 27 & 3.7 \\
\hline Others* & 30 & 4.2 \\
\hline \multicolumn{3}{|l|}{ Origin of residence } \\
\hline Rural & 412 & 56.8 \\
\hline Urban & 313 & 43.2 \\
\hline \multicolumn{3}{|l|}{ Year of study } \\
\hline First year & 192 & 26.5 \\
\hline Second year & 221 & 30.5 \\
\hline Third year & 166 & 22.9 \\
\hline Fourth year & 82 & 11.3 \\
\hline Fifth year & 64 & 8.8 \\
\hline
\end{tabular}

Ethnicity, others* : siltie, tigre, and kefa; ETB: Ethiopian Birr.

lifetime. The mean difference of CGPA with gender is statistically significant $(p$ value $<0.001$ ). The mean differences of CGPA with substance related variables were also statistically significant (Table 2).

3.3. Substance Use Characteristics of the Students. From the total students who participated in the study, $207(28.6 \%)$ of them used at least one substance in the last 12 months since the data collection time; and from those who use substance, $86.5 \%$ of them uses alcohol, $35.7 \%$ use khat, and $19.8 \%$ use tobacco products. From the total students who participated in the study, $24.7 \%$ of them use alcohol, $10.2 \%$ of them use khat, and $5.7 \%$ of them use tobacco products in the last one year since the data collection time. More than half of substance users started to use substance in their high school life before joining university (Table 3 ).

3.4. Correlation of Selected Variables with Students' Cumulative Grade Point Average. Using different substances like tobacco, khat, and alcoholic beverages had negative correlation with students CGPA (Table 4).

3.5. Association of Academic Performance with Substance Use and Other Predictors. The final model of multiple linear regression explained $45 \%$ of the variation in reported Cumulative Grade Point Average (CGPA) of the students. 
TABLE 2: Mean difference of CGPA with respect to substance use and other selected variables, 2015.

\begin{tabular}{|c|c|c|c|c|}
\hline Variables & $\begin{array}{c}\text { Frequency } \\
n(\%)\end{array}$ & $\begin{array}{c}\text { CGPA } \\
\text { mean }(\mathrm{SD})\end{array}$ & $t$ & $p$ value \\
\hline \multicolumn{5}{|l|}{ Gender } \\
\hline Male & $482(66.5)$ & $3.05(0.48)$ & \multirow{2}{*}{8.55} & \multirow{2}{*}{$<0.001$} \\
\hline Female & $243(33.5)$ & $2.72(0.49)$ & & \\
\hline \multicolumn{5}{|l|}{ Age group } \\
\hline Below mean age & $454(62.6)$ & $2.91(0.52)$ & \multirow{2}{*}{-1.38} & \multirow{2}{*}{0.17} \\
\hline Above mean age & $271(37.4)$ & $2.97(0.51)$ & & \\
\hline \multicolumn{5}{|l|}{ Residence } \\
\hline Rural & $412(56.8)$ & $2.96(0.51)$ & \multirow{2}{*}{1.69} & \multirow{2}{*}{0.09} \\
\hline Urban & $313(43.2)$ & $2.89(0.52)$ & & \\
\hline \multicolumn{5}{|l|}{ Parent substance use } \\
\hline Yes & $160(22.1)$ & $2.92(0.57)$ & \multirow{2}{*}{-0.46} & \multirow{2}{*}{0.65} \\
\hline No & $565(77.9)$ & $2.94(0.49)$ & & \\
\hline \multicolumn{5}{|c|}{ Lifetime substance use } \\
\hline Yes & $240(33.1)$ & $2.82(0.55)$ & \multirow{2}{*}{-4.47} & \multirow{2}{*}{$<0.001$} \\
\hline No & $485(66.9)$ & $2.99(0.48)$ & & \\
\hline \multicolumn{5}{|l|}{ Substance abuse* } \\
\hline Yes & $98(13.5)$ & $2.64(0.57)$ & \multirow{2}{*}{-6.15} & \multirow{2}{*}{$<0.001$} \\
\hline No & $627(86.5)$ & $2.98(0.49)$ & & \\
\hline \multicolumn{5}{|l|}{ Current alcohol } \\
\hline Yes & $179(24.7)$ & $2.78(0.58)$ & \multirow{2}{*}{-4.74} & \multirow{2}{*}{$<0.001$} \\
\hline No & $546(75.3)$ & $2.98(0.48)$ & & \\
\hline \multicolumn{5}{|l|}{ Current khat } \\
\hline Yes & $74(10.2)$ & $2.56(0.51)$ & \multirow{2}{*}{-6.67} & \multirow{2}{*}{$<0.001$} \\
\hline No & $651(89.8)$ & $2.97(0.50)$ & & \\
\hline \multicolumn{5}{|l|}{ Current smoking } \\
\hline Yes & $41(5.7)$ & $2.34(0.41)$ & \multirow{2}{*}{-7.84} & \multirow{2}{*}{$<0.001$} \\
\hline No & $684(94.3)$ & $2.97(0.50)$ & & \\
\hline \multicolumn{5}{|l|}{ Hostel user } \\
\hline Yes & $518(71.4)$ & $2.98(0.51)$ & \multirow{2}{*}{3.95} & \multirow{2}{*}{$<0.001$} \\
\hline No & $204(28.6)$ & $2.81(0.51)$ & & \\
\hline
\end{tabular}

SD: standard deviation. * based on CAGE-AID score.

The variables with significant association to academic performance were male gender $(B=0.35,95 \% \mathrm{CI}$ : $0.19,0.52)$, urban origin of residence $(\mathrm{B}=-0.19,95 \% \mathrm{CI}:-0.32,-0.06)$, current smoking ( $\mathrm{B}=-0.27,95 \% \mathrm{CI}:-0.46,-0.09)$, chewing khat at least weekly ( $\mathrm{B}=-0.24,95 \% \mathrm{CI}: 0.44,-0.04)$, having intimate friend who uses substance $(\mathrm{B}=-0.17,95 \% \mathrm{CI}:-0.31$, $-0.03)$, and drinking alcohol on a daily basis $(\mathrm{B}=-0.51,95 \%$ CI: $-0.79,-0.23$ ) (Table 5).

\section{Discussion}

This study clearly indicated that substance use is becoming a huge concern among university students. The overall prevalence of substance use among Wolaita Sodo University students was $28.6 \%$. The most frequently consumed substance by the students was alcohol, followed by khat and tobacco products, respectively. This finding was consistent with the study done in Southern Iran but lower than the study conducted in Northern Ethiopia [3, 12]. Alcohol was consumed by $24.7 \%$ of the students and this was consistent with the study conducted in different higher education institutions in Ethiopia; it was 21.6\% among Addis Ababa University medical students, $20 \%$ in Haramaya University students, and $21.7 \%$ in college students of Southern Ethiopia $[19,20]$. However, the finding in this study was lower than the study conducted among Axum University students in which 
TABLE 3: Substance use and some selected variables of students with respect to gender, 2015.

\begin{tabular}{|c|c|c|c|c|c|}
\hline \multirow{2}{*}{ Variables } & \multicolumn{2}{|c|}{ Gender } & \multirow{2}{*}{$\chi^{2}$} & \multirow{2}{*}{ df } & \multirow{2}{*}{$p$ value } \\
\hline & Male $n(\%)$ & Female $n(\%)$ & & & \\
\hline \multicolumn{6}{|l|}{ Alcohol use } \\
\hline Never & $358(49.4)$ & $188(25.8)$ & \multirow{3}{*}{1.5} & \multirow{3}{*}{2} & \multirow{3}{*}{0.47} \\
\hline Monthly or less & $91(12.6)$ & $37(5.1)$ & & & \\
\hline At least weekly & $33(4.6)$ & $18(2.5)$ & & & \\
\hline \multicolumn{6}{|l|}{ Smoking } \\
\hline Never smoke & $453(62.5)$ & $231(31.9)$ & \multirow{2}{*}{0.3} & \multirow{2}{*}{1} & \multirow{2}{*}{0.55} \\
\hline Smoker & $29(4.0)$ & $12(1.7)$ & & & \\
\hline \multicolumn{6}{|l|}{ Khat chewing } \\
\hline Never & $425(58.6)$ & $226(31.2)$ & \multirow{3}{*}{5.3} & \multirow{3}{*}{2} & \multirow{3}{*}{0.07} \\
\hline Monthly or less & $24(3.3)$ & $10(1.4)$ & & & \\
\hline At least weekly & $33(4.6)$ & $7(1.0)$ & & & \\
\hline \multicolumn{6}{|c|}{ Parent substance use } \\
\hline Yes & $113(15.6)$ & $47(6.5)$ & \multirow{2}{*}{1.6} & \multirow{2}{*}{1} & \multirow{2}{*}{0.21} \\
\hline No & $369(50.9)$ & $196(27.0)$ & & & \\
\hline \multicolumn{6}{|c|}{ Substance user friend } \\
\hline Yes & $181(25.0)$ & $56(7.7)$ & \multirow{2}{*}{15.5} & \multirow{2}{*}{1} & \multirow{2}{*}{$<0.001$} \\
\hline No & $301(41.5)$ & $187(25.8)$ & & & \\
\hline \multicolumn{6}{|l|}{ CAGE-AID score } \\
\hline$<2$ & $408(56.3)$ & $219(30.2)$ & \multirow{2}{*}{4.1} & \multirow{2}{*}{1} & 0.04 \\
\hline$>2$ & $74(10.2)$ & $24(3.3)$ & & & \\
\hline Current substance & & & & & \\
\hline Yes & $145(20.0)$ & $62(8.6)$ & 1.7 & 1 & 0.19 \\
\hline No & $337(46.5)$ & $181(25.0)$ & & & \\
\hline Lifetime substance & & & & & \\
\hline No & $311(42.9)$ & $174(24.0)$ & 3.7 & 1 & 0.06 \\
\hline Yes & $171(23.6)$ & $69(9.5)$ & & & \\
\hline Age & & & & & \\
\hline$\leq 21$ years & $264(36.4)$ & $190(26.4)$ & 37.8 & 1 & $<0.001$ \\
\hline$>21$ years & $218(30.1)$ & $53(7.3)$ & & & \\
\hline Residence & & & & & \\
\hline Rural & $289(39.8)$ & $123(17.0)$ & 57 & 1 & 0.02 \\
\hline Urban & $193(26.6)$ & $120(16.6)$ & & & \\
\hline Pocket money & & & & & \\
\hline$\leq 200 \mathrm{ETB}$ & $138(19)$ & $69(9.5)$ & 0.01 & 1 & 0.9 \\
\hline$>200$ ETB & $344(47.4)$ & $174(20.0)$ & & & \\
\hline
\end{tabular}

TABLE 4: Correlation of CGPA and selected variables among Wolaita Sodo University students, 2015.

\begin{tabular}{lcr}
\hline Variables & CGPA & $p$ value \\
\hline Drinking on daily basis & Correlation coefficient $(r)$ & -0.22 \\
Chew khat at least weekly & -0.23 & $<0.001$ \\
Smoking & -0.30 & $<0.001$ \\
Problematic use of substance (based on CAGE-AID) & -0.22 & $<0.001$ \\
Male gender & 0.30 & $<0.001$ \\
\hline
\end{tabular}


TABLE 5: Linear regression for substance use and academic performance among students, 2015.

\begin{tabular}{|c|c|c|}
\hline Variables & Beta & $\mathrm{B}(95 \% \mathrm{CI})$ \\
\hline (Constant) & $\ldots$ & $2.24(0.89,3.59)$ \\
\hline \multicolumn{3}{|l|}{ Age of the student } \\
\hline$\ldots$ & 0.03 & $0.01(-0.04,0.06)$ \\
\hline \multicolumn{3}{|l|}{ Sex } \\
\hline \multicolumn{3}{|l|}{ Female } \\
\hline Male & 0.29 & $0.35(0.19,0.52)^{* * *}$ \\
\hline \multicolumn{3}{|l|}{ Marital status } \\
\hline \multicolumn{3}{|l|}{ Single } \\
\hline Ever married & -0.11 & $-0.27(-0.58,0.04)$ \\
\hline In open relationship & -0.05 & $-0.08(-0.27,0.11)$ \\
\hline \multicolumn{3}{|l|}{ Origin of residence } \\
\hline \multicolumn{3}{|l|}{ Rural } \\
\hline Urban & -0.17 & $-0.19(-0.32,-0.06)^{* *}$ \\
\hline \multicolumn{3}{|l|}{ Year of study } \\
\hline$\ldots$ & 0.02 & $0.01(-0.06,0.07)$ \\
\hline \multicolumn{3}{|l|}{ Current smoking } \\
\hline Yes & -0.19 & $-0.27(-0.46,-0.09)$ \\
\hline \multicolumn{3}{|l|}{ No } \\
\hline \multicolumn{3}{|l|}{ Current khat chewing } \\
\hline \multicolumn{3}{|l|}{ Never } \\
\hline Monthly or less & -0.004 & $-0.01(-0.20,0.19)$ \\
\hline At least weekly & -0.17 & $-0.24(-0.44,-0.04)^{*}$ \\
\hline \multicolumn{3}{|c|}{ Having intimate friend who uses substance } \\
\hline \multicolumn{3}{|l|}{ No } \\
\hline Yes & -0.15 & $-0.17(-0.31,-0.03)^{*}$ \\
\hline \multicolumn{3}{|l|}{ Parent substance use } \\
\hline Yes & 0.02 & $0.03(-0.10,0.16)$ \\
\hline \multicolumn{3}{|l|}{ No } \\
\hline \multicolumn{3}{|l|}{ Hostel service user } \\
\hline Yes & 0.08 & $0.09(-0.06,0.24)$ \\
\hline \multicolumn{3}{|l|}{ No } \\
\hline \multicolumn{3}{|c|}{ Happy for using substance } \\
\hline Yes & -0.04 & $-0.04(-0.18,0.09)$ \\
\hline \multicolumn{3}{|l|}{ No } \\
\hline \multicolumn{3}{|c|}{ Any illness during the stay in the university } \\
\hline Yes & 0.09 & $0.18(-0.04,0.40)$ \\
\hline \multicolumn{3}{|l|}{ No } \\
\hline Interest in department ( & & \\
\hline No & -0.01 & $-0.02(-0.19,0.15)$ \\
\hline Yes & & \\
\hline Problematic substance $u$ & & \\
\hline Yes & -0.09 & $-0.10(-0.24,0.04)$ \\
\hline No & & \\
\hline Current substance use & & \\
\hline Yes & 0.06 & $0.47(-0.48,1.43)$ \\
\hline No & & \\
\hline Religion & & \\
\hline Orthodox & & \\
\hline Muslim & -0.03 & $-0.06(-0.31,0.18)$ \\
\hline Protestant & -0.07 & $-0.09(-0.24,0.06)$ \\
\hline
\end{tabular}


TABLE 5: Continued.

\begin{tabular}{|c|c|c|}
\hline Variables & Beta & B $(95 \% \mathrm{CI})$ \\
\hline \multicolumn{3}{|l|}{ Substance starting time } \\
\hline \multicolumn{3}{|l|}{ Never } \\
\hline \multicolumn{3}{|l|}{ Before joining WSU ${ }^{\S}$} \\
\hline At 1st year & -0.07 & $-0.09(-0.25,0.07)$ \\
\hline Second year \& above & -0.01 & $-0.02(-0.19,0.16)$ \\
\hline \multicolumn{3}{|l|}{ Drinking alcohol } \\
\hline \multicolumn{3}{|l|}{ Never } \\
\hline Monthly & -0.08 & $-0.11(-0.27,0.05)$ \\
\hline Weekly & -0.01 & $-0.02(-0.21,0.17)$ \\
\hline Daily & -0.22 & $-0.51(-0.79,-0.23)^{* * *}$ \\
\hline
\end{tabular}

the alcohol consumption was $32.8 \%$. In addition, the finding of this study was much more less than the study conducted in Trinidad and Tobago university students in which the sixmonth alcohol consumption was 70\%, and Turkey University students in which it was $37.9 \%[11,14,21]$. This might be due to cultural and socioeconomic differences.

The prevalence of khat use was $10.2 \%$ and this finding was in line with the study conducted among medical students of Addis Ababa University which was 7\% [4]. But the finding in this study was lower than the findings from Haramaya University, 23.6\%, and elsewhere in Southern Ethiopia, 27.7\% $[19,20]$. The possible explanation for the observed difference might be due to environmental conditions like the availability of the specific substance.

Tobacco products were used by $5.7 \%$ of the students and it was consistent with other studies done among University students in Ethiopia [16]. However, the finding was lower as compared with the study done among Haramaya University students which was $10.8 \%$ and Italian University students in which current smoking was $24 \%[19,22]$.

The use of substance is known for its significant association with mental distress and consequently this mental distress can affect the students' academic performance negatively [23-25]. As the study conducted at Jimma university students indicated, substance use was associated with low academic performance [9]. This may be due to the consequences of substance use towards social, economic, physical, and psychological aspects of the student. There may be conflict with parents or friends, health problems, financial hardships, and emotional disturbance because of substance use $[26,27]$.

Students who were current smoker had significantly high risk of poor academic performance (lower score of Cumulative Grade Point Average) as compared with nonsmokers. Smoking is known to be a getaway substance for other illicit drug uses, high risk drinking behavior, and high risk sexual behavior as well. Those complex interactions with other risky behaviors make smoking the important predictor of poor academic performance [6].
Khat chewing was also associated significantly and negatively with academic performance of the students. The reported CGPA of the students who were chewing khat at least weekly was less than those who were not chewing khat at all. Even though most students perceived that khat use improves academic performance [28], it was associated with poor CGPA score as indicated by this study. Khat chewing usually tends to be more ceremonial activity and most of the khat sessions took long durations followed with smoking and drinking alcohol, which may interfere with students' academic activities negatively [29, 30].

Drinking alcoholic beverages was also significantly and negatively associated with the academic performance. Those who were drinking on a daily basis had scored significantly lower CGPA than those who never drank alcoholic beverages in the last 12 months. Alcohol clouds judgment and can make the student be careless about academic and other success issues. This finding was consistent with the study done in United Kingdom University students in which alcohol consumption was negatively associated with academic performance [31]. In the study conducted elsewhere among adolescents, academic difficulties associated with alcohol consumption were reported [2].

Not only using substances was associated with academic performance, but also having an intimate friend who uses substance was associated. Peer pressure is known to be an important predictor to shape adolescents behavior either in good or bad way. The CGPA of students who have intimate friend who uses substance was significantly lower as compared with those who did not have intimate friend who uses substance. This finding was supported by the research done in Ethiopia among higher institution students in which peer pressure was one of the factors associated with students' substance use $[3,16]$.

The other predictors with significant association with students' academic performance were sex and residence, in which male students scored significantly higher CGPA than females and the CGPA of students from urban area was less than that of the students from rural area. Though evidence 
from developed countries reports that female students' academic performance is better as compared with males [32, 33], this is not the case in resource limited setting where female enrollment and academic performance is in lower rate. Communities' attitude for female education, higher gender based violence and disproportionate cultural, and socioeconomic and psychological burdens in female students might contribute to poor academic achievement of female students [34-36].

\section{Conclusion and Recommendations}

Substance use was high among Wolaita Sodo University students. Current smoking, khat chewing, drinking alcohol, having intimate friend who uses substance, and urban residence were significantly associated with poor CGPA score. The high prevalence of substance use and its association with poor academic performance demand from the universities to have a good control of substance and to implement youth friendly activities to bring behavioral change on their students. It is also better to empower female students by making them active participants in class as well as in teaching learning activities in order to increase their CGPA.

\section{Abbreviations \\ ASSIST: $\quad$ The Alcohol, Smoking and Substance Involvement Screening Test \\ CAGE-AID: Cut down, Annoyed, Guilty, Eye opener-Adapted to Include Drugs \\ CGPA: $\quad$ Cumulative Grade Point Average \\ DSM-5: Diagnostic and Statistical manual of Mental disorders 5th edition \\ WHO: World Health Organization.}

\section{Additional Points}

Limitations of the Study. This study did not include substances other than tobacco products, alcohol, and khat. Interaction effect of these substances with academic achievement was also not assessed.

\section{Conflicts of Interest}

All authors declare that they have no conflicts of interest.

\section{Authors' Contributions}

Tesfa Mekonen conceived the original idea and was involved in proposal development, design, and data collection and analysis and in all stages of the research project. Wubalem Fekadu, Tefera Chane Mekonnen, and Shimelash Bitew Workie participated in proposal writing, design and literature search, data collection, analysis, and write-up of the paper. All authors read and approved the final manuscript.

\section{Acknowledgments}

The authors like to express their gratefulness for all study participants for their genuine participation, Wolaita Sodo
University for financial and material support, and Wolaita Sodo University staff members.

\section{References}

[1] M. Osain and V. Alekseevic, "The effect of alcohol use on academic performance of university students," Annals of General Psychiatry, vol. 9, Supplement 1, p. S215, 2010.

[2] A. I. Balsa, L. M. Giuliano, and M. T. French, "The effects of alcohol use on academic achievement in high school," Economics of Education Review, vol. 30, no. 1, pp. 1-15, 2011.

[3] G. T. Aklog and T. T. Girmay, "Assessment of substance abuse and associated factors among students of debre markos poly technique college in debre markos town, East Gojjam Zone, Amhara Regional State, Ethiopia, 2013," Global Journal of Medical Research, vol. 13, no. 4, 2013.

[4] W. Deressa and A. Azazh, "Substance use and its predictors among undergraduate medical students of Addis Ababa University in Ethiopia," BMC Public Health, vol. 11, article 660, 2011.

[5] A. B. Makanjuola, T. O. Daramola, and A. O. Obembe, "Psychoactive substance use among medical students in a Nigerian university," World Psychiatry, vol. 6, no. 2, pp. 112-114, 2007.

[6] F. Venturelli, A. Poscia, G. Carrozzi, L. Sampaolo, A. Bargellini, and W. Ricciardi, "Magnavita N: prevalence of alcohol abuse among workers in Italy," La Medicina Del Lavoro, vol. 108, no. 1, pp. 52-63, 2017.

[7] Control CfD, Prevention, others: Alcohol and other drug use and academic achievement. Atlanta, GA: Centers for Disease Control and Prevention 2011.

[8] R. G. Cox, L. Zhang, W. D. Johnson, and D. R. Bender, "Academic performance and substance use: findings from a state survey of public high school students," Journal of School Health, vol. 77, no. 3, pp. 109-115, 2007.

[9] K. Meressa, A. Mossie, and Y. Gelaw, "Effect of substance use on academic achievement of health officer and medical students of Jimma University, Southwest Ethiopia," Ethiopian Journal of Health sciences, vol. 19, no. 3, pp. 155-163, 2009.

[10] L. Atwoli, P. A. Mungla, M. N. Ndung'u, K. C. Kinoti, and E. M. Ogot, "Prevalence of substance use among college students in Eldoret, western Kenya," BMC Psychiatry, vol. 11, article 34, 2011.

[11] C. Bakar, D. Gündogar, H. I. Ozisik Karaman, and I. Maral, "Prevalence and related risk factors of tobacco, alcohol and illicit substance use among university students," European Journal of Psychiatry, vol. 27, no. 2, pp. 97-110, 2013.

[12] A. Sahraian, M. Sharifian, B. Omidvar, and A. Javadpour, "Prevalence of substance abuse among the medical students in southern Iran," Shiraz E Medical Journal, vol. 11, no. 4, pp. 198202, 2010.

[13] M. S. van Heerden, A. T. Grimsrud, S. Seedat, L. Myer, D. R. Williams, and D. J. Stein, "Patterns of substance use in South Africa: results from the South African Stress and Health study," South African Medical Journal, vol. 99, no. 5, pp. 358-366, 2009.

[14] M. Gebreslassie, A. Feleke, and T. Melese, "Psychoactive substances use and associated factors among Axum University students, Axum Town, North Ethiopia," BMC Public Health, vol. 13, no. 1, article 693, 2013.

[15] A. A. Reda, A. Moges, S. Biadgilign, and B. Y. Wondmagegn, "Prevalence and determinants of khat (Catha edulis) chewing among high school students in eastern ethiopia: a crosssectional study," PLoS ONE, vol. 7, no. 3, Article ID e33946, 2012. 
[16] A. A. Reda, A. Moges, B. Yazew, and S. Biadgilign, "Determinants of cigarette smoking among school adolescents in eastern Ethiopia: a cross-sectional study," Harm Reduction Journal, vol. 9, article 39, 2012.

[17] WHO ASSIST Working Group, “The Alcohol, smoking and substance involvement screening test (ASSIST): development, reliability and feasibility," Addiction, vol. 97, no. 9, pp. 1183-1194, 2002.

[18] R. Humeniuk, R. Ali, T. F. Babor et al., "Validation of the alcohol, smoking and substance involvement screening test (ASSIST)," Addiction, vol. 103, no. 6, pp. 1039-1047, 2008.

[19] G. Tesfaye, A. Derese, and M. T. Hambisa, "Substance use and associated factors among University Students in Ethiopia: a Cross-Sectional Study," Journal of Addiction, vol. 2014, article e969837, 2014.

[20] L. Samuel and M. T. Angamo, "Substance use and sexual risk behavior and factors associated with HIV transmission in southern Ethiopia," IJPSR, vol. 3, pp. 1080-1086, 2012.

[21] A. M. Dhanookdhary, A. M. Gomez, R. Khan et al., "Substance use among university students at the St augustine campus of the University of the West Indies," West Indian Medical Journal, vol. 59, no. 6, pp. 641-649, 2010.

[22] A. Poscia, P. Parente, E. M. Frisicale, A. A. Teleman, C. De Waure, and M. L. Di Pietro, "Risky behaviours among university students in Italy," Annali dell'Istituto Superiore di Sanita, vol. 51, no. 2, pp. 111-115, 2015.

[23] T. Damena, A. Mossie, and M. Tesfaye, "Khat chewing and mental distress: a Community based study, in Jimma city, Southwestern Ethiopia," Ethiopian Journal of Health Sciences, vol. 21, no. 1, pp. 37-45, 2011.

[24] S. Mancevska, L. Bozinovska, J. Tecce, J. Pluncevik-Gligoroska, and E. Sivevska-Smilevska, "Depression, anxiety and substance use in medical students in the Republic of Macedonia," Bratislava Medical Journal, vol. 109, no. 12, pp. 568-572, 2008.

[25] Y. Dessie, J. Ebrahim, and T. Awoke, "Mental distress among university students in Ethiopia: A cross sectional survey," Pan African Medical Journal, vol. 15, article 95, 2013.

[26] L. A. Tsvetkova and N. A. Antonova, "The prevalence of drug use among university students in St. Petersburg, Russia," Psychology in Russia: State of the Art, no. 1, pp. 86-94, 2013.

[27] B. O. Abdu-Raheem, "Sociological Factors To Drug Abuse And The Effects On Secondary School Students Academic Performance In Ekiti And Ondo States, Nigeria," Contemporary Issues in Education Research (CIER), vol. 6, no. 2, p. 233, 2013.

[28] E. Gebrehanna, Y. Berhane, and A. Worku, "Khat chewing among Ethiopian University Students-a growing concern," BMC Public Health, vol. 14, no. 1, article 1198, 2014.

[29] R. M. Al-Sanosy, "Pattern of khat abuse and academic performance among secondary school and college students in jazan region, kingdom of saudi arabia (ksa)," Journal of Family and Community Medicine, vol. 16, no. 3, pp. 89-95, 2009.

[30] B. Tilahun, A. Gedefaw, and A. Asefa, "Predictors of selfreported academic performance among undergraduate medical students of Hawassa University, Ethiopia," Advances in Medical Education and Practice, vol. 6, pp. 305-315, 2015.

[31] W. El Ansari, C. Stock, and C. Mills, "Is Alcohol Consumption Associated with Poor Academic Achievement in University Students?" International Journal of Preventive Medicine, vol. 4, no. 10, pp. 1175-1188, 2013.

[32] A. Rahafar, M. Maghsudloo, S. Farhangnia, C. Vollmer, and C. Randler, "The role of chronotype, gender, test anxiety, and conscientiousness in academic achievement of high school students," Chronobiology International, vol. 33, no. 1, pp. 1-9, 2016.

[33] M. Sheard, "Hardiness commitment, gender, and age differentiate university academic performance," British Journal of Educational Psychology, vol. 79, no. 1, pp. 189-204, 2009.

[34] C. E. Jordan, J. L. Combs, and G. T. Smith, "An Exploration of Sexual Victimization and Academic Performance Among College Women," Trauma, Violence, and Abuse, vol. 15, no. 3, pp. 191-200, 2014.

[35] D. Teferra and P. G. Altbach, African Higher Education: An International Reference Handbook, Indiana University Press, Bloomington, Ind, USA, 2003.

[36] D. Teferra and P. G. Altbach, "African higher education: challenges for the 21st century," Higher Education, vol. 47, no. 1, pp. 21-50, 2004. 


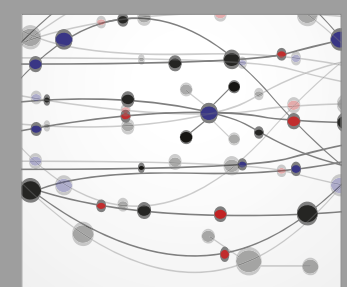

The Scientific World Journal
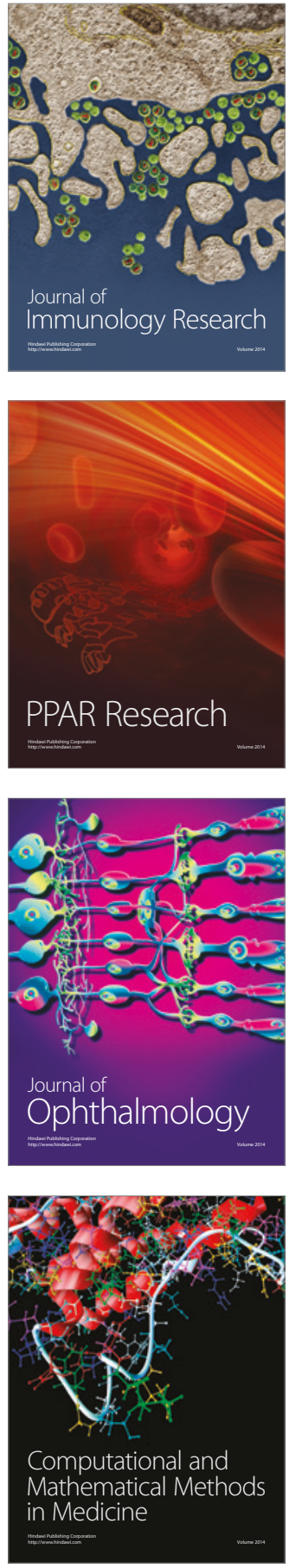

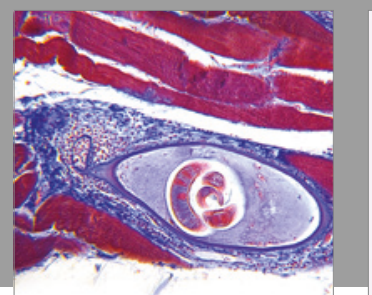

Gastroenterology Research and Practice
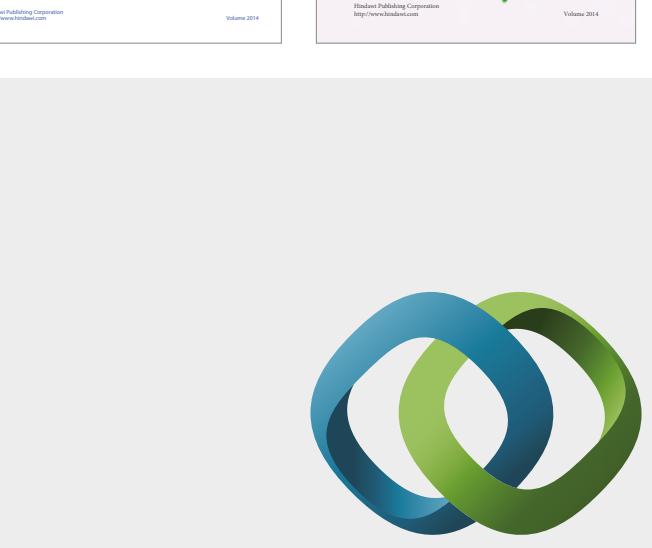

\section{Hindawi}

Submit your manuscripts at

https://www.hindawi.com
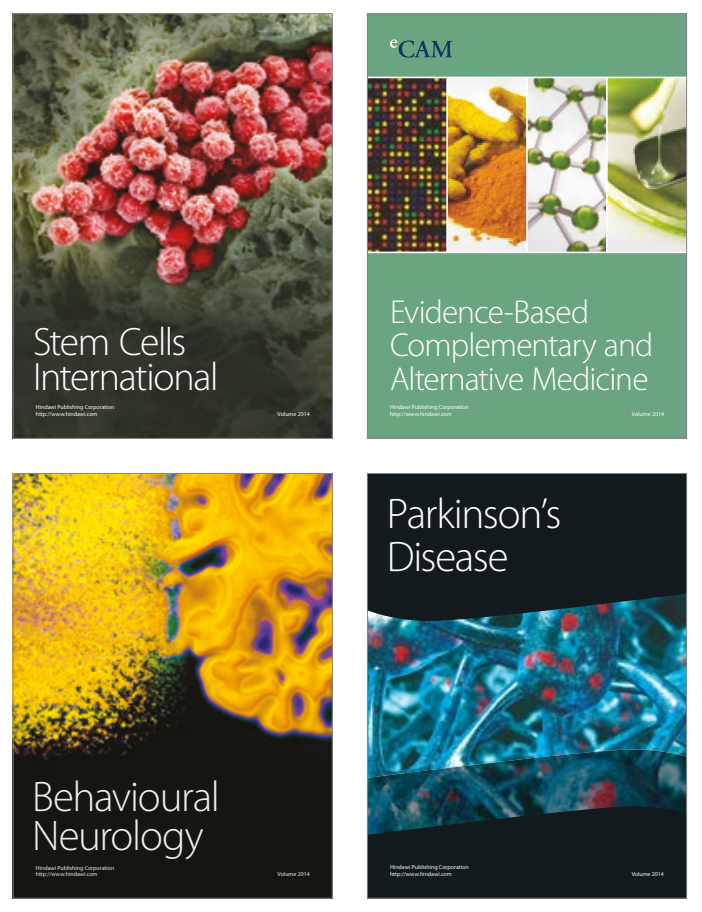
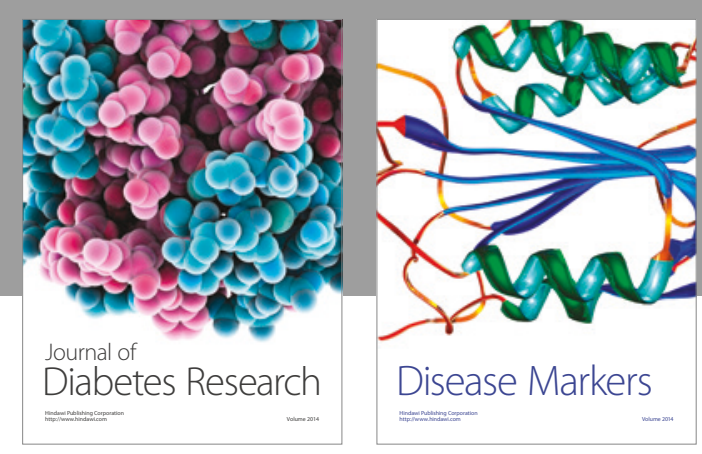

Disease Markers
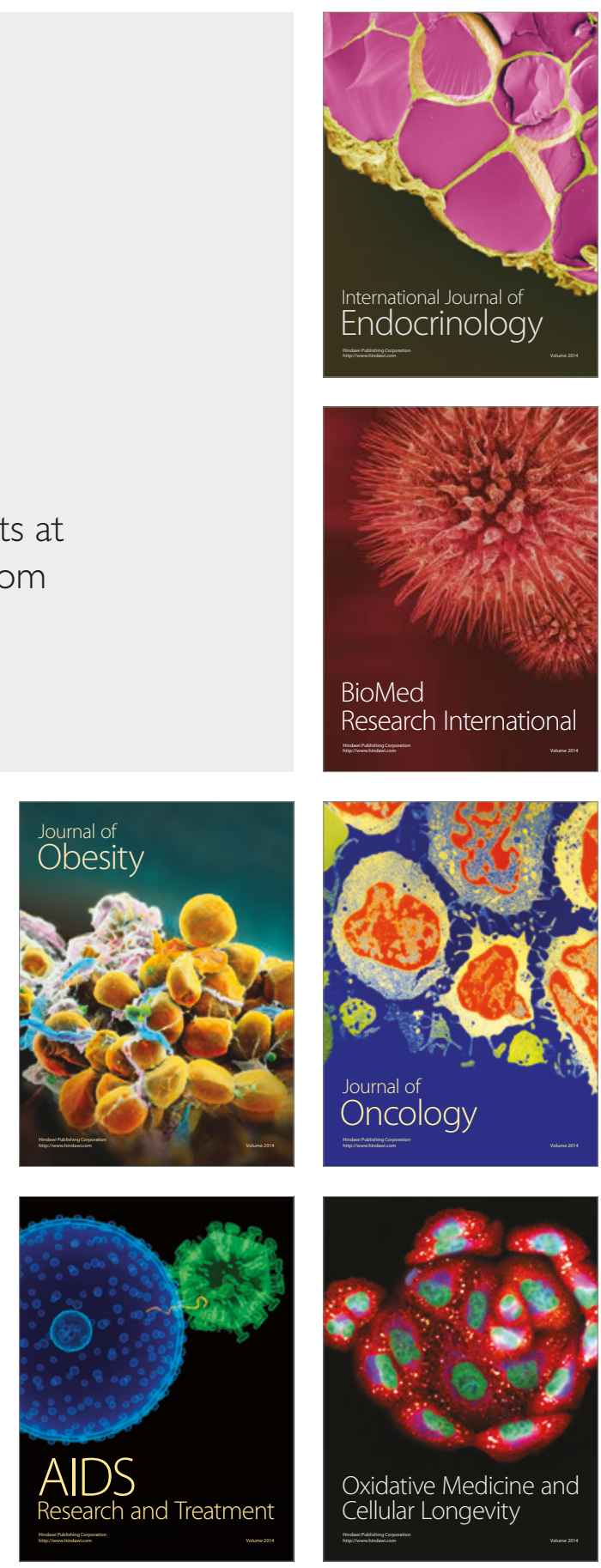